\title{
Adventure Tourism Products: Price, Duration, Size, Skill, Remoteness
}

\begin{abstract}
To test whether commercial tourism products in different adventure activity sectors have different functional characteristics, I took part in tours offered by 75 operators worldwide and analysed price per person per day, duration, prior skill requirements, remoteness, group size and client-toguide ratios. There is an enormous range of variation. Some activities overlap but some are clearly distinguishable, on commercial as well as operational criteria. Products can be arranged on a scale from low-volume, high-difficulty, high-price to high-volume, low-difficulty, low-price. There are recognisable signatures for some subsectors, but not all.
\end{abstract}

(100 words)

Keywords: adventure, products, price, patterns, skill 


\section{INTRODUCTION}

Adventure tourism has grown rapidly in recent years as outdoor recreation has become increasingly commercialised (Johnson and Edwards 1994; Buckley 1998; Travel Industry Association of America, 2005). In much of the developed world, outdoor recreation is currently treated more as a purchasable short-term holiday experience than as a gradually-acquired lifetime skill (Buckley 2004; Kane and Zink 2004). This may be due in part to the increasing use of adventure imagery in retail advertising (Buckley 2003; Cater 2005).

Adventure tourism has been defined in various terms (Buckley 2000; Bentley and Page 2001; Hudson 2002; Swarbrooke et al. 2003; Page et al. 2005). Broadly, it means guided commercial tours, where the principal attraction is an outdoor activity that relies on features of the natural terrain, generally requires specialised equipment, and is exciting for the tour clients. The clients may operate the equipment themselves or they may simply be passengers. This is an empirical product-oriented definition rather than a philosophical people-oriented one. Different clients on the same tour may have different skills, demographics, emotions, expectations and experiences, but they still all bought the same tour.

Typical activities in adventure tours include climbing, caving, abseiling, seakayaking, whitewater kayaking, rafting, diving, snorkeling, skiing, snow boarding, surfing, sail boarding, sailing, ballooning, skydiving, parapenting, horse riding, mountain biking, snowmobiling and off-road driving.

Tourism is a commercial industry as well as a social phenomenon. Tour providers package and sell commercial products to retail clients. The dynamics of the industry, the behaviour of the 
people involved, their destinations and impacts are all intimately linked with the structure of these products. If we are to understand any of the more subtle aspects of the tourism sector, surely we must first appreciate the core components, the retail tourism products.

To date, however, the actual commercial products offered by adventure tourism operators do not seem to have been subject to any coherent and comprehensive review and analysis. As noted by More and Averill (2003) more generally: "The most neglected part of recreation research may be the actual composition of an activity." There is an extensive research literature on adventure tourism (Buckley, 2006) but very little of this examines the structure of commercial tour products. The structure and composition of adventure tours have been described to some degree by Tabata (1992) for diving, Arnould and Price (1993) for rafting, Shackley (1998) for snorkelling, Davis et al. (1997) for whaleshark watching, Scott and Laws (2004) for whalewatching, Ryan (1998) for crocodile watching, Wilson and Tisdell (2001) for sea turtles, Jennings (2003) for marine tours, Leedie (2003) for mountaineering, Shackley (1996) for wildlife tours, and Cloutier (2003) for adventure tourism more generally. None of these, however, focussed principally on the tours as saleable products.

Here, therefore, I examine price, duration, group size, skill requirements and remoteness for a set of commercial adventure tours involving various activities and locations, to test whether we can identify recognisable product signatures both for the sector as a whole and for separate subsectors.

\section{METHODS}

From 2001 to 2005 I took part in a set of commercial adventure tours involving various activities in various countries. The companies are listed in Table 1. From the perspective of the tour 
participants I was not identified as a researcher, and I did not carry out any interviews. I made passive observations of operating practices and procedures following a systematic protocol (Buckley, 2006), and recorded the results as field notes. Detailed descriptions of the tour products, and my experiences in auditing them are available in Buckley (2006). Here I present and analyse only the statistical parameters of product design. The parameters examined are: price, duration, remoteness, group size, client-to-guide ratio, and prior skill requirements. These are all considerations which may affect purchasing decisions in various ways.

During late 2005 I re-examined descriptions of each tour on the relevant operator's website, and updated information on price, duration and itinerary. I also included a small number of additional tours which I had not audited in person during the past five years, but where I had obtained relevant information either (a) by commissioning colleagues to carry out similar audits; (b) by carrying out previous audits myself and checking that no changes had occurred; or (c) by carrying out private trips on the same itinerary and observing commercial groups without joining them directly. A total of 78 individual audits are presented here.

This is an exploratory analysis intended to search for broad product signatures. There are $<10$ individual data points (tour products) for each activity type shown in Figure 3. This is a considerable increase over previous published literature on adventure tourism products, but still inadequate for detailed statistical analysis. In addition, the selection of products in each subsector is not necessarily representative. Some of the products considered, for example, include upmarket accommodation and meals, whereas others only include the activity itself. Prices are also influenced by currency exchange rates. Results are therefore presented principally in a graphical manner, with limited statistical analysis as appropriate. 


\section{RESULTS}

Figure 1 plots price per person per day in US\$ against tour duration in days or weeks, using a log-log scale. Most of the major adventure activities can be distinguished broadly along these two product dimensions, but some overlap, especially near the centre of each scale. Figure 2 shows the mean price per day, \pm 1 standard deviation, for the nine activities where five or more products were audited.

For the reasons outlined earlier, these data are exploratory rather than representative and detailed statistical analysis would not necessarily be reliable, since sample sizes are small and the individual tour products in each activity subsector are not fully comparable. As indicated in Figure 2, the various water-based activities such as whitewater rafting and kayaking (including longer river journeys), seakayaking and surfing have similar prices per day. Diving is somewhat more expensive, because of the need for specialist equipment including compressors. Heliboarding/skiing is significantly more expensive, because helicopters are used effectively full time. The price difference between the heliboard tours $(n=5)$ and the various raft, kayak and surf tours $(\mathrm{n}=33)$ is significant at $\mathrm{p}<0.01$ (unequal-variances t-test). This applies even though some of the heliboard tours are introductory 1-day trips at the lower end of the market and some of the raft and kayak tours are top-end trips involving helicopter access or expedition boat support. Interestingly, the wildlife watching tours are also expensive (Figure 2): much more so, say, than the hiking tours. This is because most of these particular tours involve small groups with highly skilled guides and trackers viewing large and potentially dangerous animals in relatively remote areas, with specialised transport and upmarket accommodation. These are the types of wildlife-watching experiences which are marketed as adventure tourism. 
Remoteness and prior skill requirements for each major activity are summarised in Figure 3. Remoteness is characterised by ease of access. Prior skill requirements provide an indirect measure of risk. For these parameters, the differences between individual products within each activity subsector generally outweigh the differences between subsectors, so the distinction between subsectors is weak. The same subsector may include tours which offer first ascents, descents or traverses under dangerous and difficult conditions; and tours which include a day's training for complete novices in complete safety.

Group size and client-to-guide ratios are summarised in Table 2. Group sizes listed are for an entire tour run by the same company at the same place on the same day for clients who have purchased the same product. The clients may be divided into subsidiary groups for operational purposes. Thus, group size for a rafting trip includes all the rafts travelling together, and group size for a heliski trip includes all the subgroups shuttled by the same machines in the same area.

Two thirds of these tours take 6-20 clients at a time. Only 13\% take five clients or fewer, and approximately 22\% take 21 clients or more. The small-group tours are generally those that need little equipment, such as hiking; those where equipment limits group size, such as rafts or helicopters; or those with prior skill requirements, such as whitewater kayaking.

The large-group tours are either those which can readily replicate smaller units to form a large group, such as rafting; or those where equipment necessarily has a large passenger capacity, such as expedition cruise vessels. For the data in Table 2, the number of tour products with group size over 20 is significantly higher for rafting than for kayaking, river expeditions and seakayaking (chi-square $=12.2, \mathrm{P}<0.001)$. 
Client-to-guide ratios are determined principally by risk, difficulty and skill requirements. Some trips take one or more guides for each client, as well as a support crew. For trips with less demanding skill requirements where the main function of the guide is to manage logistics, there may only be one guide per 20 or 30 clients; though such trips may perhaps barely qualify as adventure tourism. For a wide range of activities and trips, the characteristic client-to-guide ratio is between 5:1 and 7:1; either because this represents the capacity of an individual vehicle, helicopter or boat, or because this is about as many people as a single guide can keep an eye on at any one moment. Client-to-guide ratios are significantly higher for rafting than kayaking (chi-square = 14.8, $\mathrm{P}<0.001)$.

\section{DISCUSSION AND CONCLUSIONS}

The results presented above indicate that most adventure tourism activities have a recognisable commercial signature as measured by duration and price per person per day. Some, however, show a bimodal pattern. Heliski operations in the Himalayas and the Canadian Rockies, for example, are all designed around a 1-week all-inclusive package, irrespective of operator; but those in New Zealand are sold as single-day trips.

The main bulk of the adventure market consists of high-volume low-difficulty products for unskilled clients. The leading edge, in contrast, consists of low-volume, high-cost products which require prior skills, involve significant individual risk for clients, and operate in more remote and inhospitable areas (Buckley, 2004). Even the most skilled and remote commercial tours, however, are overshadowed by adventure recreation exploits and one-off expeditions (Figure 4). Between these extremes there is an enormous diversity in the design, duration, places and prices for 
different adventure tours. Even so, however, there are identifiable patterns in price and duration, and in group size and client-to-guide ratio, for different adventure activities.

The results presented here consider each of the main product characteristics independently. This is an exploratory approach necessitated by the relatively small sample sizes. Skill requirements, group size, client-to-guide ratio, access and remoteness, duration, equipment and accommodation may all be interrelated, and all can affect the price per person per day. These interrelationships may be apparent for individual tour products, but such data are somewhat anecdotal. To test the relationships between product characteristics in a statistically reliable sense will require a larger set of data from specific activity subsectors, so as to apply standard multivariate analytical techniques. Information on some of these attributes is available in tour operator marketing materials. These could readily provide a data set with more numerous cases but less reliable data. This approach would, however, form a valuable complement to the full-scale product audits reported here. 
TABLE 1

\section{ADVENTURE TOUR OPERATORS AUDITED}

Adrift, Uganda

AJ Hackett Bungy, New Zealand

Aurora Expeditions, Svalbard

Blackfeather, Canada

Canadian Mountain Holidays, Canada

Conservation Corporation Africa, Tanzania

Conservation Corporation Africa, Zanzibar

Dhonveli Beach Resort, Maldives

Endless River Adventures, Costa Rica

Expeditions Inc, USA

Explorer Shipping, Antarctica

Himachal Helicopter Skiing, India

Jump the Beach, Australia

Kenya Wildlife, Kenya

Lalati Dive Resort, Fiji

Methven Heliski, New Zealand

Nagigia Surf Resort, Fiji

NOLS, Australia

Natural High, New Zealand

OARS, USA

Oregon Peak, USA

Queenstown Rafting, New Zealand

Raft and Rainforest, Australia

Raleigh Expeditions, Australia

Reynella Station, Australia

Rivers Fiji, Fiji

Savaii Surfaris, Samoa

Shearwater Adventures, Zimbabwe

Southern Sea Ventures, Fiji

Surtrek, Ecuador

Team Gorky, Russia

Ultimate Descents, New Zealand

Uncharted Africa Safaris, Botswana

Wild Rivers, USA

Wildwater Adventures, Australia

World Expeditions, Australia

World Expeditions, Nepal
Africa Wildlife Safaris, Uganda

Allardice's Ultimate Descents, Nepal

Balloon Down Under, Australia

Boojum Expeditions, Mongolia

Carlos Colares, Brazil

Cons Corp Africa, South Africa

Delphis Diving, Maldives

Earth Science Expeditions, China

Expediciones Chile, Chile

Explore Kamchatka, Russia

Harris Mountains Heliski, New Zealand

John Gray’s Sea Canoe, Thailand

Kaikoura Helicopters, New Zealand

King Dive, Australia

Mentawai Sanctuary, Indonesia

Mike Wiegele Heli Skiing, Canada

National Outdoor Leadership School, Alaska

Natural Habitat Adventures, Canada

Ningaloo Blue, Australia

Ocean River, New Zealand

Paddy Pallins, Australia

Quicksilver Dive, Australia

Raging Thunder, Australia

Rangitata Rafts, New Zealand

Ride World Wide, Patagonia

Salani Surf Resort, Samoa

Shangri-La River Expeditions, Tibet

Southern Sea Ventures, Australia

Southern Sea Ventures, Norway

Taka Dive, Australia

Tiger Tops Karnali, India

Ultimate Hikes, New Zealand

Walindi Resort, Papua New Guinea

Wilderness Safaris, South Africa

Willis's Walkabouts, Australia

World Expeditions, Nepal

Yacu Amu, Ecuador

Note: Countries indicate location of tours audited, not necessarily company headquarters. 
TABLE 2

GROUP SIZES AND CLIENT-TO-GUIDE RATIOS

\begin{tabular}{llllllllll}
\hline \multirow{2}{*}{ Activity (n> 5 only) } & $\mathbf{n}$ & \multicolumn{3}{c}{ Group size } & \multicolumn{5}{c}{ Client-to-guide ratio } \\
& & $\mathbf{1 - 5}$ & $\mathbf{6 - 2 0}$ & $\mathbf{2 1 - 5 0}$ & $\mathbf{> 5 0}$ & $<\mathbf{1}$ & $\mathbf{2 - 4}$ & $\mathbf{5 - 9}$ & $>\mathbf{1 0}$ \\
\hline \multirow{2}{*}{ Whitewater rafting } & 17 & 1 & 2 & 14 & 0 & 0 & 2 & 15 & 0 \\
Whitewater kayaking & 9 & 1 & 5 & 3 & 0 & 0 & 8 & 1 & 0 \\
River expeditions & 10 & 1 & 4 & 5 & 0 & 3 & 2 & 5 & 0 \\
Seakayaking & 8 & 1 & 7 & 0 & 0 & 0 & 3 & 4 & 1 \\
Diving & 9 & 1 & 6 & 1 & 1 & 0 & 3 & 2 & 4 \\
Surfing & 5 & 0 & 5 & 0 & 0 & 0 & 0 & 2 & 3 \\
Heliski/board & 5 & 0 & 3 & 2 & 0 & 0 & 3 & 1 & 1 \\
Wildlife watching & 6 & 0 & 6 & 0 & 0 & 0 & 5 & 0 & 1 \\
& & & & & & & & & \\
\hline Total & $\mathbf{6 9}$ & $\mathbf{5}$ & $\mathbf{3 8}$ & $\mathbf{2 5}$ & $\mathbf{1}$ & $\mathbf{3}$ & $\mathbf{2 6}$ & $\mathbf{3 0}$ & $\mathbf{1 1}$ \\
\hline
\end{tabular}


FIGURE 1

PRICES AND DURATIONS FOR ADVENTURE TOURISM PRODUCTS AUDITED

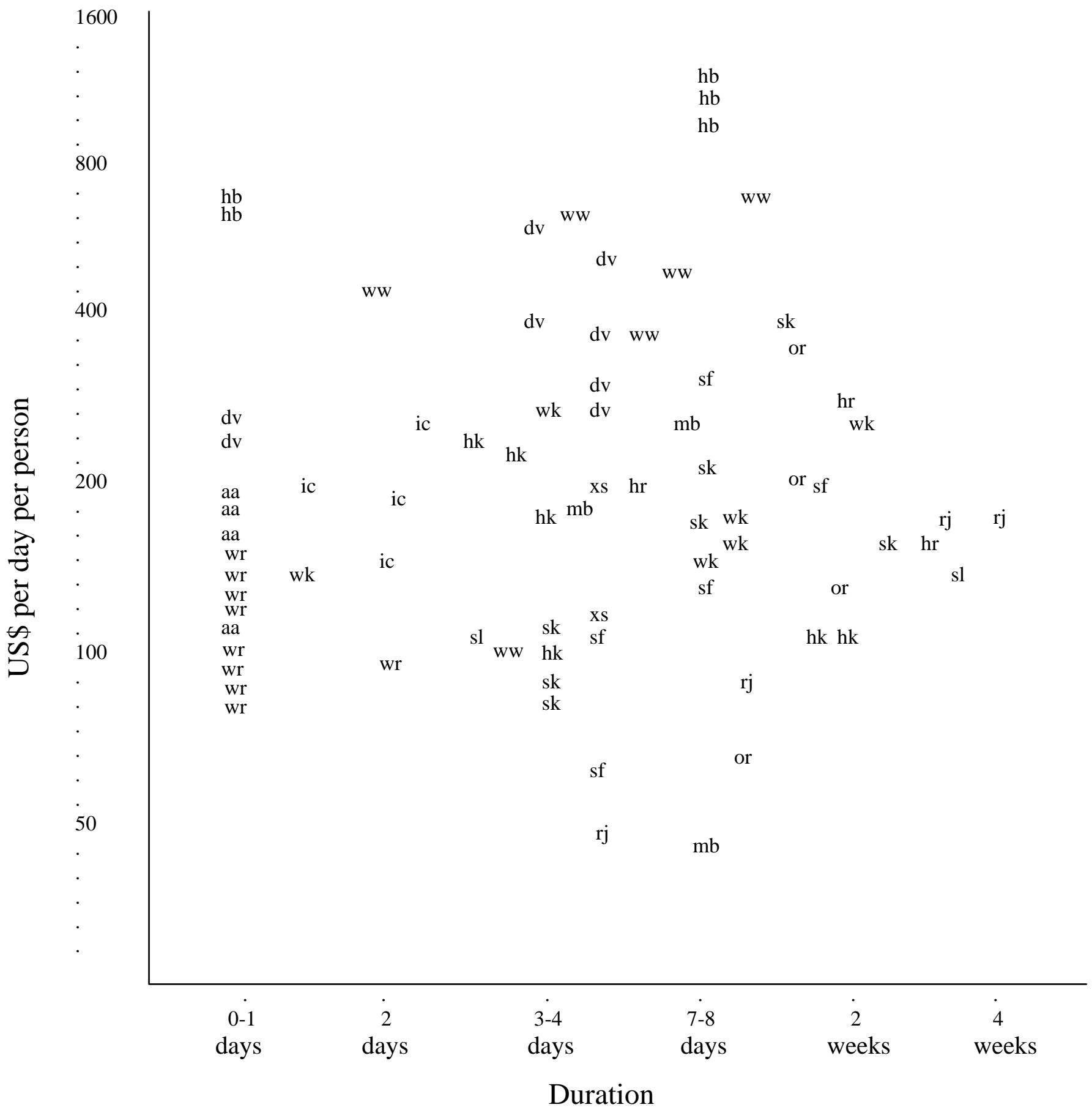

Codes: aa, aerial adventures; dv, diving; hb, heliboarding/skiing; hk, hiking; hr, horse riding; ic, ice climbing; mb, mountain biking; or, off-road driving; rj, river journeys; sf, surfing; sk, seakayaking; wk, whitewater kayaking; wr, whitewater rafting; ww, wildlife watching; xs, cross-country skiing. 
FIGURE 2

PRICES PER DAY, MEANS AND STANDARD DEVIATIONS

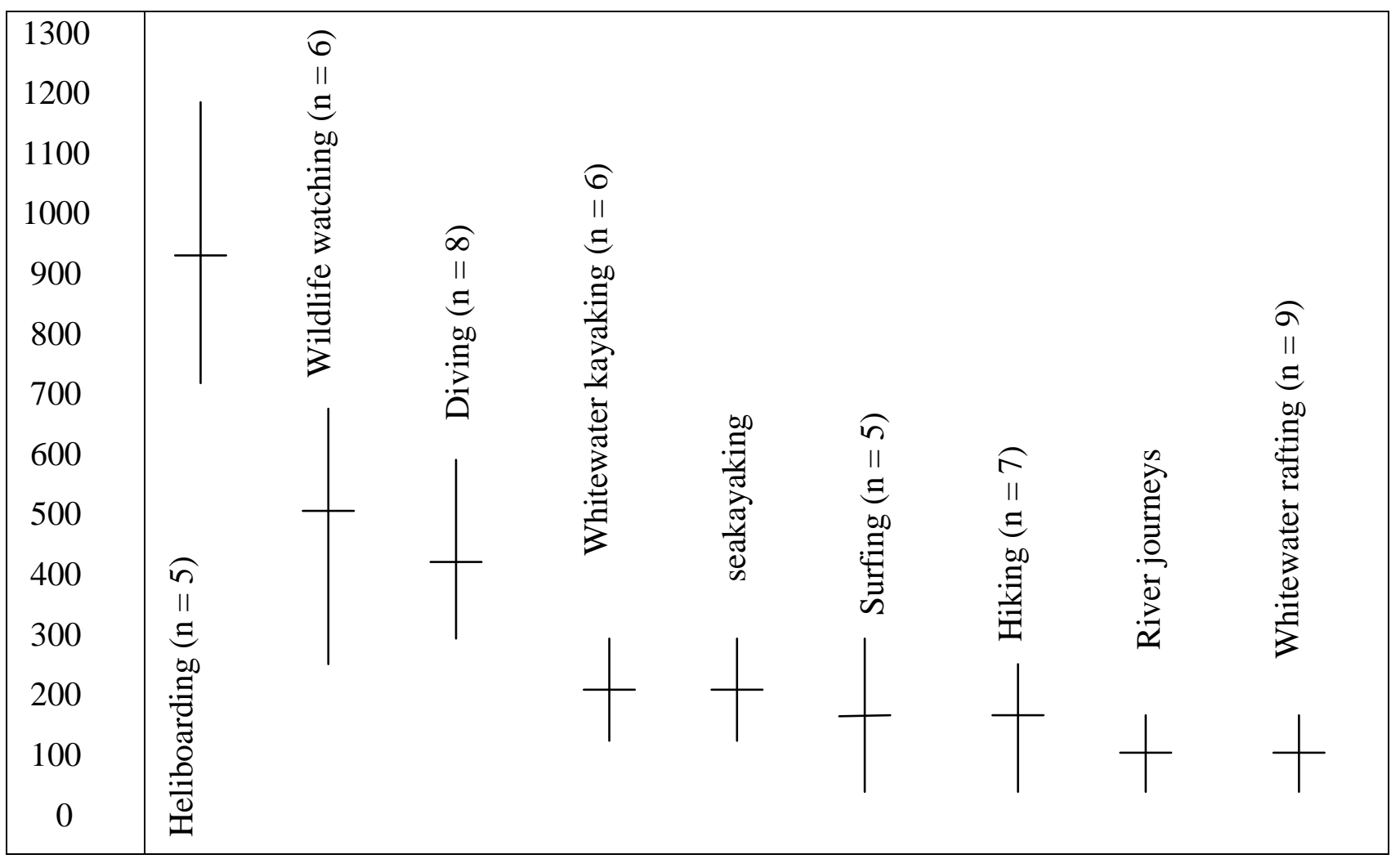

Note: Error bars show one standard deviation either side of the mean price per day for the activity concerned. 
FIGURE 3

SKILL REQUIREMENTS AND REMOTENESS

\begin{tabular}{|c|c|c|c|c|c|c|c|c|c|c|c|c|c|c|}
\hline Activity & Pri & Sk & & & & & & Rel & oten & ss, A & ccess & & & \\
\hline $\begin{array}{l}\text { Note: prior skills and } \\
\text { remoteness refer to } \\
\text { commercial tours } \\
\text { available, not private } \\
\text { trips }\end{array}$ & 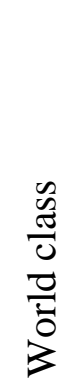 & 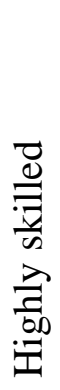 & 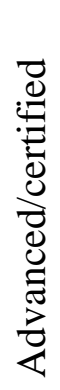 & 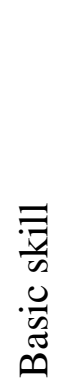 & 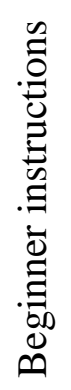 & 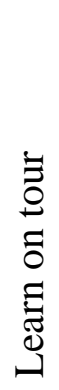 & 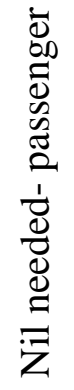 & 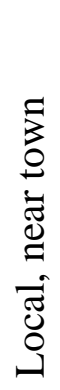 & 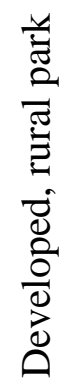 & 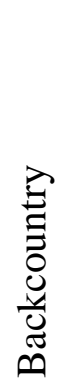 & 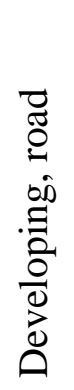 & 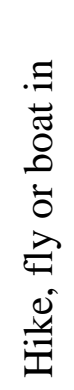 & 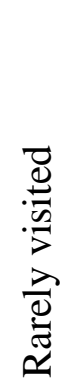 & 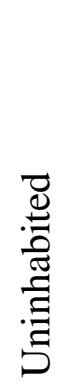 \\
\hline River expeditions & * & $*$ & * & $*$ & * & $*$ & & & & $*$ & $*$ & * & $*$ & \\
\hline Whitewater kayaking & $*$ & $*$ & $*$ & $*$ & * & & & * & * & $*$ & $*$ & $*$ & $*$ & * \\
\hline Whitewater rafting & & $*$ & $*$ & $*$ & $*$ & $*$ & $*$ & $*$ & $*$ & $*$ & $*$ & $*$ & $*$ & $*$ \\
\hline Seakayaking & & $*$ & $*$ & $*$ & $*$ & * & & & * & $*$ & $*$ & $*$ & $*$ & $*$ \\
\hline Sailing & & $*$ & * & * & * & $*$ & $*$ & $*$ & * & $*$ & * & $*$ & $*$ & $*$ \\
\hline Expedition cruises & & & & & & & $*$ & & & & & & $*$ & $*$ \\
\hline Diving & $*$ & $*$ & $*$ & $*$ & $*$ & & & $*$ & $*$ & $*$ & $*$ & $*$ & $*$ & $*$ \\
\hline Surfing & $*$ & $*$ & $*$ & $*$ & $*$ & & & $*$ & $*$ & $*$ & $*$ & $*$ & $*$ & $*$ \\
\hline Heliski/snowboard & $*$ & $*$ & $*$ & & & & & & & $*$ & $*$ & $*$ & $*$ & $*$ \\
\hline Cross-country skiing & & $*$ & $*$ & $*$ & $*$ & & & & & $*$ & $*$ & $*$ & $*$ & * \\
\hline Ice climbing & & $*$ & $*$ & $*$ & $*$ & & & & $*$ & $*$ & $*$ & $*$ & $*$ & * \\
\hline Mountaineering & & $*$ & $*$ & $*$ & $*$ & & & & & $*$ & $*$ & $*$ & $*$ & * \\
\hline Hiking and bushwalking & & & * & $*$ & * & & & & & $*$ & $*$ & $*$ & $*$ & \\
\hline Horse riding & & $*$ & $*$ & $*$ & $*$ & & & $*$ & $*$ & $*$ & $*$ & $*$ & & \\
\hline Mountain biking & & $*$ & $*$ & $*$ & $*$ & & & & $*$ & $*$ & $*$ & $*$ & & \\
\hline Off-road safaris & & & $*$ & $*$ & $*$ & $*$ & $*$ & & $*$ & & $*$ & $*$ & $*$ & \\
\hline Wildlife watching & $*$ & $*$ & $*$ & $*$ & $*$ & $*$ & $*$ & & & $*$ & $*$ & $*$ & $*$ & $*$ \\
\hline Ballooning & & & & & & & & $*$ & $*$ & & $*$ & & & \\
\hline Skydiving & & $*$ & & & & & $\dagger^{*}$ & & $\dagger *$ & & & & $*$ & $*$ \\
\hline Scenic/heli flights & & & & & & & & $*$ & $*$ & & & $*$ & & \\
\hline Bungy jumping & & & & & & & & $*$ & $*$ & & & & & \\
\hline
\end{tabular}


FIGURE 4

THE ADVENTURE ACTIVITY SCALE: VOLUME CF. DIFFICULTY.

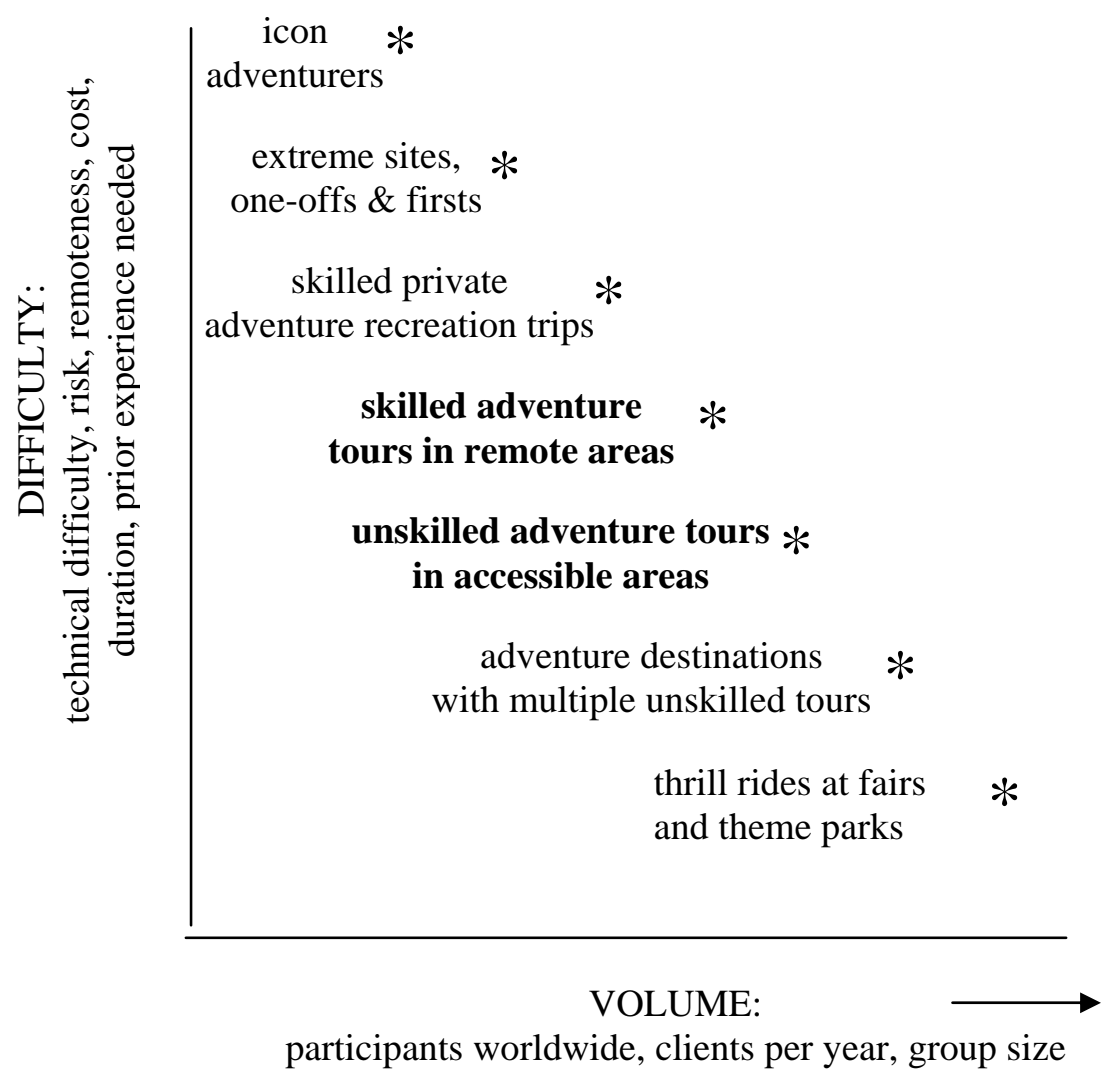

Note: All products audited here are in the two categories shown in bold text. 


\section{REFERENCES}

Arnould, Eric J. and Linda L. Price (1993). "River magic: extraordinary experience and the extended service encounter.” Journal of Consumer Research, 20 (1): 24-45.

Beedie, Paul (2003). "Mountain guiding and adventure tourism: reflections on the choreography of the experience.” Leisure Studies, 22 (2): 147-167.

Bentley, Tim A. and Stephen J. Page (2001). "Scoping the extent of adventure tourism accidents.” Annals of Tourism Research, 28 (3): 705-726.

Buckley, Ralf C. (1998). “Ecotourism megatrends.” Australian International Business Review, 1998 (December): 52-54.

Buckley Ralf C. (2000). “NEAT trends: current issues in nature, eco and adventure tourism.” International Journal of Tourism Research, 2 (6): 437-444.

Buckley, Ralf C. (2003). “Adventure tourism and the clothing, fashion and entertainment industries.” Journal of Ecotourism, 2 (2): 126-134.

Buckley, Ralf C. (2004). “Skilled commercial adventure: the edge of tourism.” In New Horizons in Tourism, edited by Tej V. Singh. CAB International, Oxford, pp. 37-48.

Buckley, Ralf C. (2006). Adventure Tourism. CAB International, Oxford.

Cater, Carl 2005. Looking the part: The relationship between adventure tourism and the outdoor fashion industry. In Taking Tourism to the Limits, edited by Ryan, Chris, Stephen Page, and Michelle Aicken. Elsevier, London

Cloutier, Ross (2003). The business of adventure tourism. In Sport and Adventure Tourism edited by Simon Hudson. Haworth Hospitality Press, USA, pp. 241-272.

Davis, Derrin, Simon Banks, Alastair Birtles, Peter Valentine and Michael Cuthill (1997). "Whale sharks in Ningaloo Marine Park: managing tourism in an Australian marine protected area.” Tourism Management, 18 (5): 259-271. 
Jennings, Gayle (2003). “Marine tourism.” In Sport and Adventure Tourism, edited by Simon Hudson. Haworth Hospitality Press, USA, pp. 125-164.

Johnson, Barbara R. and Ted Edwards (1994). “The commodification of mountaineering.” Annals of Tourism Research, 21 (3): 459-478.

Kane, Maurice J. and Robyn Zink (2004). "Package adventure tours: markers in serious leisure careers.” Leisure Studies, 23 (4): 329-345.

More, Thomas A. and James R. Averill (2003). “The structure of recreation behavior.” Journal of Leisure Research, 35: 372-395.

Page, Stephen J., Tim Bentley, and Linda. Walker (2005). “Scoping the nature and extent of adventure tourism operations in Scotland: how safe are they?” Tourism Management, 26 (3): 381-397.

Ryan, Chris (1998). “Saltwater crocodiles as tourist attractions.” Journal of Sustainable Tourism. 6 (4): 314-327.

Scott, Noel and Eric Laws (2004). "Whale watching - the roles of small firms in the evolution of a new Australian niche market.” In Small Firms in Tourism: International Perspectives, edited by Rhodri Thomas. Elsevier Science, Amsterdam, pp. 153-166.

Shackley, Myra (1996a). Wildlife Tourism. International Thomson Business Press, London. Shackley, Myra (1998). “'Stingray City' - managing the impact of underwater tourism in the Cayman Islands.” Journal of Sustainable Tourism, 6 (4): 328-338.

Tabata, Ray S. (1992). “Scuba diving holidays.” In Special Interest Tourism, edited by Betty Weiler, and C. Michael Hall. Belhavan Press, London, UK, pp. 171-184.

Travel Industry Association of America (2005). “Adventure Travel Report.” http://www.tia.org Last viewed 25 November 2005.

Wilson, Clevo and Clem A. Tisdell (2001). “Sea turtles as a non-consumptive tourism resource especially in Australia.” Tourism Management, 22 (3): 279-288. 